\title{
Properties of high-temperature melts using levitation*
}

\author{
Paul C. Nordine ${ }^{\dagger}$, J. K. Richard Weber, and Johan G. Abadie \\ Containerless Research, Inc., 906 University Place, Evanston, Illinois 60201, USA
}

\begin{abstract}
Containerless conditions allow well-controlled investigation of liquids at high temperatures. Levitation methods used for this purpose are reviewed, and their application is illustrated by discussion of the properties and behavior of deeply undercooled yttriumaluminum-oxide melts.
\end{abstract}

\section{INTRODUCTION}

Levitation techniques are useful tools for high-temperature melt property studies. They eliminate the problem of reaction with containers and allow deep undercooling of melts. The containerless conditions may be obtained by opposing gravity with a levitation force, or by allowing an entire experiment to freefall. This paper addresses these methods and results of recent research using containerless techniques. It emphasizes research on properties of undercooled liquids of the yttrium aluminum garnet (YAG) composition, $\mathrm{Y}_{3} \mathrm{Al}_{5} \mathrm{O}_{12}$, and novel products formed from yttria-alumina melts.

\section{LEVITATION METHODS}

In this section we review methods that have been applied to perform high-temperature experiments under containerless conditions. The emphasis is on experiments of long duration on liquids. A major source of interest and support for this work is in its extension to low gravity conditions where the forces required to perform containerless experiments are small. In low gravity, control of sedimentation, stirring, and convection is obtained to facilitate the study of transport properties and other investigations that require quiescent conditions.

\section{Magnetic levitation}

Most levitation methods oppose gravity by exerting a force on the surface of the sample. An exception where the force is exerted throughout the sample volume is the recently demonstrated levitation of diamagnetic materials in a magnetic field gradient [1]. A superconducting magnet was used to obtain magnetic fields up to $30 \mathrm{~T}$ and field gradients of $-4200 \mathrm{~T}^{2} / \mathrm{m}$. Materials with a magnetic susceptibility more negative than $\chi_{S}=-2.9 \times 10^{-9} \mathrm{~m}^{3} / \mathrm{Kg}$ were levitated. The method is applicable, for example, for levitation of $\mathrm{H}_{2} \mathrm{O}, \mathrm{SiO}_{2}, \mathrm{~B}_{2} \mathrm{O}_{3}$, and $\mathrm{Al}_{2} \mathrm{O}_{3}$. Experiments with levitation and laser beam heating and melting of $\mathrm{BK} 7$ glass showed that $\chi_{S}$ increases with temperature.

\section{Electromagnetic levitation (EML)}

EML, patented by Muck in 1923 [2], is one of the oldest techniques for containerless experiments. A typical EML coil has reversed winding of upper and lower sections energized by an RF power supply.

\footnotetext{
*Lecture presented at the $10^{\text {th }}$ International Conference on High Temperature Materials Chemistry (HTMC-X), Jülich, Germany, 10-14 April 2000. Other presentations are published in this issue, pp. 2101-2186.

†Corresponding author: E-mail: pnordine@ containerless.com
} 
The EM frequency must be large enough that the EM skin depth is less than the sample radius, typically $200-400 \mathrm{kHz}$ for 5-mm-diameter metallic samples.

The levitation force is proportional to the gradient, $\mathrm{d} B^{2} / \mathrm{d} z$, in the magnetic field intensity, and the heat input is proportional to $B^{2}$ averaged over the sample surface. An EM levitated sample thus achieves a high temperature that depends on sample density and the force of gravity. Molten samples are deformed and stirred by the EM forces.

The TEMPUS (Tiegelfreies ElektroMagnetisches Prozessieren Unter Schwerlosigkeit) facility is an electromagnetic heating and positioning system for containerless experiments in microgravity. TEMPUS employs a low-power quadrupole coil to control sample position and a higher power dipole coil for heating. Heating and positioning are not coupled, and the temperature range for containerless experiments is greatly expanded. The TEMPUS team [3] has reported experiments performed with this facility during the International Microgravity Laboratory Mission 2 (IML-2). The experiments included undercooling of liquid metals and alloys, statistics for nucleation of crystalline phases from undercooled melts, glass formation, and measurement of properties such as viscosity, surface tension, and specific heat.

\section{Electrostatic levitation (ESL)}

ESL was developed by Rhim et al. [4] for microgravity experiments. An advanced ESL is described by Rulison et al. [5]. This instrument is installed at NASA's Marshall Space Flight Center in Alabama and used in ground-based research under containerless and high vacuum conditions. Until recently, research with the ESL has emphasized work on metals such as zirconium and deep eutectic alloys, and silicon, which exhibit relatively low vapor pressures at the melting point. Recent advances have been made in the levitation and heating of oxide glasses and ceramics [6]. Surface tension and viscosity measurements under containerless conditions in an ESL, were reported by Rhim et al. [7].

Electric fields on the order of $1 \mathrm{kV} / \mathrm{mm}$ are used to levitate electrically-charged samples in the ESL and electrical discharges prevent operation in a gas environment. In principle, operation in low gravity can reduce the required field strength, allowing the use of an ambient gas atmosphere, investigation of more volatile materials, and studies of gas/liquid reactions and equilibria. A low-gravity ESL for the Space Station is under development by NASDA in Japan.

\section{Gas film levitation (GFL)}

GFL was first developed by Granier and Potard [8]. They report experiments to levitate and melt up to $10 \mathrm{~g}$ of $\mathrm{Cu}, \mathrm{Ag}$, and $\mathrm{Au}$, and $2-4 \mathrm{~g}$ of $\mathrm{Al}$ and $\mathrm{Ge}$. The sample is levitated by floating on a thin gas film formed by gas flow through a porous membrane. A furnace or EM-heated graphite susceptor may be used to achieve high temperatures.

Barbé et al. [9] used GFL to measure viscosity by a shape-relaxation method. A sample of levitated liquid was compressed by a gas film piston and then allowed to relax toward a more spherical shape under the action of surface tension forces. The quotient of viscosity and surface tension was derived from the measurements of sample shape given by the ratio of polar to equatorial radii. Viscosity values from 26 to $1.4 \times 10^{4} \mathrm{~Pa} \cdot \mathrm{s}$ were measured for a silicate glass (Schott AR glass) in the temperature range $1074-1398 \mathrm{~K}$.

\section{Aerodynamic levitation}

Aerodynamic forces can be used to suspend a sample material in a gas stream that flows from a nozzle. Solid sample spheres may be levitated and laser beam heated in low-pressure free jets [10]. This method has been used in combination with laser-induced fluorescence to obtain accurate vapor pressure and melting point measurements for pure boron [11], for which no suitable container was available. 
However, free-jet levitation becomes unstable when the samples are melted. Two solutions to this problem have been developed.

Aero-acoustic levitation (AAL) [12,13] stabilizes the free-jet levitation of liquids by application of relatively small and highly localized acoustic forces that control fluctuations in the sample position. Open access to the levitated sample facilitates noncontact property measurements, two-sided laser beam heating to minimize temperature gradients in the sample, use of splat-quenching devices, etc. The AAL method has been applied primarily in studies of oxides, with the apparatus open to the atmosphere. Undercooling of molten ceramic superconductors, $\mathrm{Al}_{2} \mathrm{O}_{3}$, aluminates, and geological materials [14], vaporization of impurities from $\mathrm{Al}_{2} \mathrm{O}_{3}$, glass formation, and crystal nucleation studies are reported [15-19].

The conical nozzle levitator (CNL) is the second method to obtain stable aerodynamic levitation of liquids. The sample is supported by gas flow in a diverging conical nozzle and laser beam heated from above. Temperatures in excess of $3000 \mathrm{~K}$ are easily realized in 3-mm-diameter oxide specimens with 250 watts of $\mathrm{CO}_{2}$ laser beam power. The $\mathrm{CNL}$ is a simple and compact device that is easily integrated within an apparatus for liquid-phase property measurements or processing experiments.

The CNL method was first used in combination with EM heating of levitated aluminum and uranium liquid [20]. Later, Coutures et al. [21] introduced $\mathrm{CO}_{2}$ laser beam heating and reported numerous investigations of liquid oxides, including structural investigations by NMR and EXAFS [22-24]. Krishnan et al. [25] developed a CNL device for synchrotron X-ray scattering measurements. Their work on molten $\mathrm{Al}_{2} \mathrm{O}_{3}, \mathrm{Y}_{2} \mathrm{O}_{3}, \mathrm{Y}_{3} \mathrm{Al}_{5} \mathrm{O}_{12}$, mullite, boron, silicon, and other liquids, and theoretical modeling of the structural results were recently reviewed by Krishnan and Price [26]. Enderby et al. [27] adapted the CNL apparatus for measurements of the electrical conductivity of molten $\mathrm{Al}_{2} \mathrm{O}_{3}, \mathrm{Ge}$, and $\mathrm{Si}$.

Additional investigations with the CNL method include the synthesis of glass fibers from rareearth aluminate compositions, by fiber pulling from deeply undercooled melts [28], liquid density measurements on molten $\mathrm{Al}_{2} \mathrm{O}_{3}$ [29], and synthesis of many new oxide glass materials [21,30].

\section{TEMPERATURE MEASUREMENT}

Optical pyrometry is the preferred method for noncontact temperature measurement in containerless experiments. Emissivity corrections are required to obtain the true temperature, $T$, from the apparent temperature, $T_{a}$, that is measured with an optical pyrometer. For a narrow-band spectral radiation pyrometer of effective wavelength, $\lambda$, Wien's approximation to Planck's law gives the relationship between $T, T_{a}$, and the spectral emissivity, $\varepsilon_{\lambda}$ :

$$
1 / T-1 / T_{a}=\lambda / C_{2} \ln \varepsilon_{\lambda}
$$

where $C_{2}=1.4388 \times 10^{-2} \mathrm{~m} \cdot \mathrm{K}$. For highly absorbing materials such as liquid metals, the emissivity can be quite small, on the order of 0.1 to 0.4 , and emissivity corrections are large. Krishnan [31,32] developed ellipsometric measurements on levitated liquids that provide the required emissivity values.

For weakly absorbing opaque materials, such as oxide liquids at high temperatures, the normal spectral emissivity, $\varepsilon_{\lambda}$, is calculated from the index of refraction, $n_{\lambda}$, as follows:

$$
\varepsilon_{\lambda}=1-\left[\left(n_{\lambda}-1\right) /\left(n_{\lambda}+1\right)\right]^{2}-\tau_{\lambda}
$$

where $\tau_{\lambda}$ is the optical transmission which equals zero for an opaque sample. For example, the value of $n_{\lambda}$ for molten yttria-alumina compositions is approximately 1.8 at $\lambda=650 \mathrm{~nm}$, which yields $\varepsilon_{\lambda}=0.92$ and a relatively small emissivity correction to apparent temperatures. Further, $n_{\lambda}$ typically exhibits a weak variation with temperature and wavelength, so that the total hemispherical emissivity for oxide liquids varies little with temperature, and can often be estimated to about $\pm 5 \%$. 
The principal problem in temperature measurement on levitated oxide liquids arises at lower temperatures where the liquid begins to become transparent (i.e., $\tau_{\lambda}$ becomes significant). The emissivity is then unknown unless in-situ optical transmission experiments are performed. Alternatively, a different pyrometer may be used to make measurements at a wavelength at which the sample is opaque. Significant transparency (at $650 \mathrm{~nm}$ ) begins to occur at temperatures below about $1500 \mathrm{~K}$ for molten yttria-alumina compositions.

\section{RESEARCH ON UNDERCOOLED MOLTEN YAG}

Yttrium aluminum garnet, $\mathrm{Y}_{3} \mathrm{Al}_{5} \mathrm{O}_{12}$ or "YAG", is a technologically important material as a host crystal for Nd:YAG lasers and for potential structural applications based on its extreme resistance to creep at high temperatures. Crystal growth is known to encounter difficulties in phase selection between the garnet phase and a metastable mixture of $\mathrm{YAlO}_{3}$ and $\mathrm{Al}_{2} \mathrm{O}_{3}$ [33]. The vapor pressure of YAG is quite low at the melting point $(2240 \mathrm{~K})$, which makes it an attractive material for containerless melt processing research. Extremely deep undercooling of the melt is possible under containerless conditions, and considerable research has been performed to investigate the properties of the liquid. In this section, we review this research which is exemplary of novel experiments that levitation methods permit.

\section{Fragile liquids}

The concept of fragile liquids, introduced by Angell [34], is of considerable interest in connection with oxide melts. Fragile liquids display (i) substantially greater heat capacity than the corresponding crystalline solid, and (ii) highly non-Arhennian temperature dependence of viscosity. For example, the viscosity of molten YAG is illustrated in Fig. 1, and compared with the strong liquid, $\mathrm{SiO}_{2}$.

Three different experiments yield the viscosity, $\eta$, vs. temperature data in Fig. 1 . The first is direct measurements at $2240-2340 \mathrm{~K}$ at temperatures above the melting point where $\eta \approx 0.04 \mathrm{~Pa} \cdot \mathrm{s}$ [35]. The second is an estimated viscosity of 30-300 Pa.s at 1600-1650 K, the temperature at which glass fibers

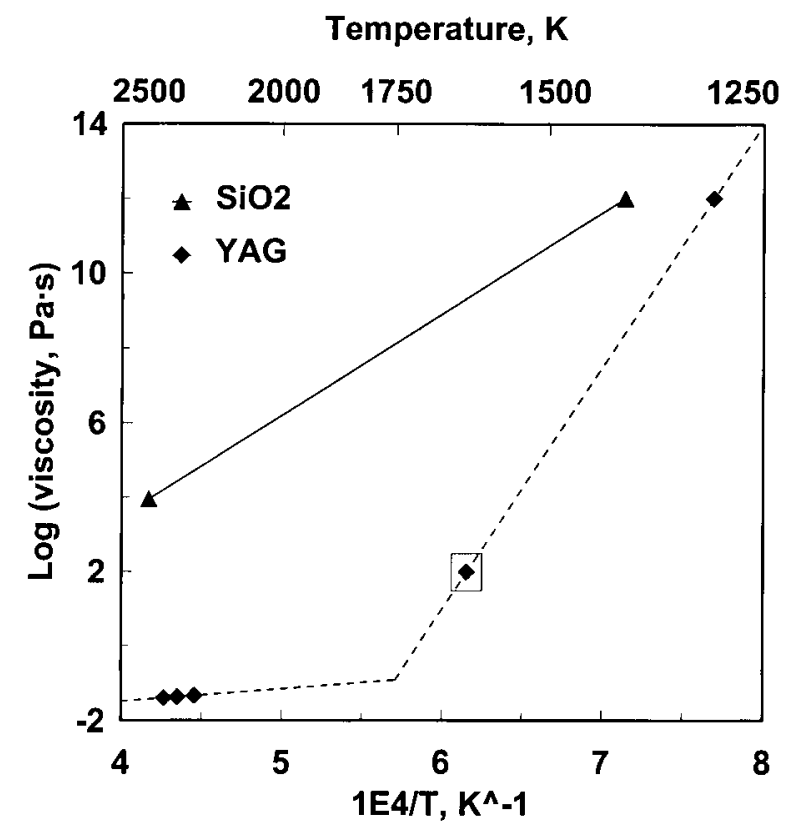

Fig. 1 Viscosity vs. temperature for a strong liquid, $\mathrm{SiO}_{2}$, and a fragile liquid, molten $\mathrm{Y}_{3} \mathrm{Al}_{5} \mathrm{O}_{12}$. 
can be pulled from the undercooled liquid [28]. The third is a value of $10^{12} \mathrm{~Pa} \cdot \mathrm{s}$ at the estimated glass transition temperature, $T_{\mathrm{g}} \approx 1300 \mathrm{~K}[36]$.

The glass transition temperature, $T_{\mathrm{g}}$, is defined as the temperature at which the heat capacity of the glassy or liquid phase displays an abrupt increase relative to the crystalline solid. If the solid-liquid heat capacity difference is substantial, the liquid will be fragile. Kauzmann [37] first discussed the thermodynamic consequences of this effect. The influence of the solid-liquid heat capacity difference [38] on the enthalpy and entropy of fusion of $\mathrm{Al}_{2} \mathrm{O}_{3}$ is illustrated in Fig. 2.

Figure 2 includes results for a hypothetical situation in which the larger value of the liquid heat capacity above $T_{\mathrm{g}}$ is assumed to continue at lower temperatures. It is seen that the entropy of fusion would then become zero at $T_{\mathrm{K}}=1050 \mathrm{~K}$, which is defined as the Kauzmann temperature. This situation is considered impossible; it follows that a lower limit on glass transition temperatures can be obtained from the heat capacity of the undercooled liquid.

Glass of the YAG composition is formed by cooling the liquid under containerless conditions. The enthalpy of fusion of YAG [39] is $420 \mathrm{~kJ} / \mathrm{mol}=21 \mathrm{~kJ} / \mathrm{g}$-atom, and the enthalpy of vitrification of the glass [40] is $13.8 \mathrm{~kJ} / \mathrm{g}$-atom. Thus, a large heat capacity difference must exist between liquid and crystalline YAG, which confirms that the undercooled liquid is fragile.

\section{Undercooling behavior of $\mathrm{Y}_{3} \mathrm{Al}_{5} \mathrm{O}_{12}$}

Coutures et al. [21] first investigated the behavior of deeply undercooled liquid $\mathrm{Y}_{3} \mathrm{Al}_{5} \mathrm{O}_{12}$. They showed that three products may be formed. Spontaneous crystallization of the melt to form a metastable mix-
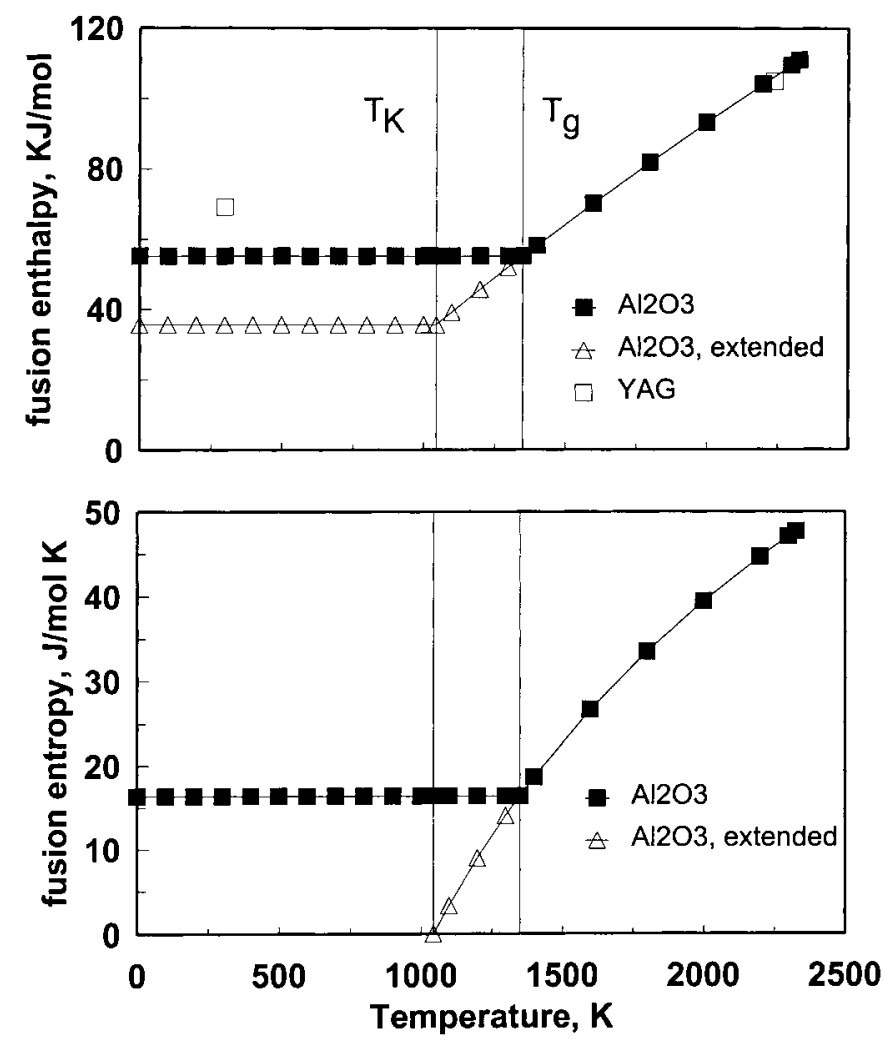

Fig. 2 Fusion enthalpy and entropy of $\mathrm{Al}_{2} \mathrm{O}_{3}$ [38] in the undercooled liquid. The enthalpies of fusion [39] and vitrification [40] of YAG are shown by open squares. 
ture of crystalline $\mathrm{YAlO}_{3}$ (yttrium aluminum perovskite, YAP) and $\alpha-\mathrm{Al}_{2} \mathrm{O}_{3}$ may occur near $1600 \mathrm{~K}$, $640 \mathrm{~K}$ below the $2240 \mathrm{~K}$ melting point of crystalline YAG. Deeper undercooling leads to spontaneous crystallization to form stable crystalline $\mathrm{Y}_{3} \mathrm{Al}_{5} \mathrm{O}_{12}$. Alternatively, glass is formed if the cooling rate exceeds ca. $200 \mathrm{~K} / \mathrm{s}$. These results have been confirmed by Nagashio and Kuribayashi [41], and in our research.

Figure 3 shows the three events that may occur upon cooling of a molten YAG sample ( $c a .3 \mathrm{~mm}$ diameter) under containerless conditions. In Figs. 3A-3C, the products are a mixture of YAP and $\alpha-\mathrm{Al}_{2} \mathrm{O}_{3}$, glass, and YAG, respectively. Formation of crystalline products is signaled by recalescence, an abrupt temperature increase due to the enthalpy of crystallization.

The results in Fig. 3 were obtained in the aero-acoustic levitator with a levitation gas flow of pure argon gas and $\mathrm{CO}_{2}$ laser beam heating to $c a$. $2500 \mathrm{~K}$ prior to quenching. Apparent temperature, $T_{a}$, was measured (at temperatures below $2000 \mathrm{~K}$ ) with a fast pyrometer whose effective wavelength was 650 $\mathrm{nm}$. Figure 3 includes $T_{a}$ vs. time (solid symbols), and $1 / T_{a}{ }^{3}$ vs. time (open symbols). The linear portion of $1 / T_{a}^{3}$ vs. $t$ shows that heat loss is primarily by radiation above $1500 \mathrm{~K}$, where the liquid is opaque and the spectral and total emissivities are essentially constant. At temperatures below $1500 \mathrm{~K}$, the liquid becomes increasingly transparent and the measured values of $T_{a}$ fall below the fit of the data at higher temperatures.
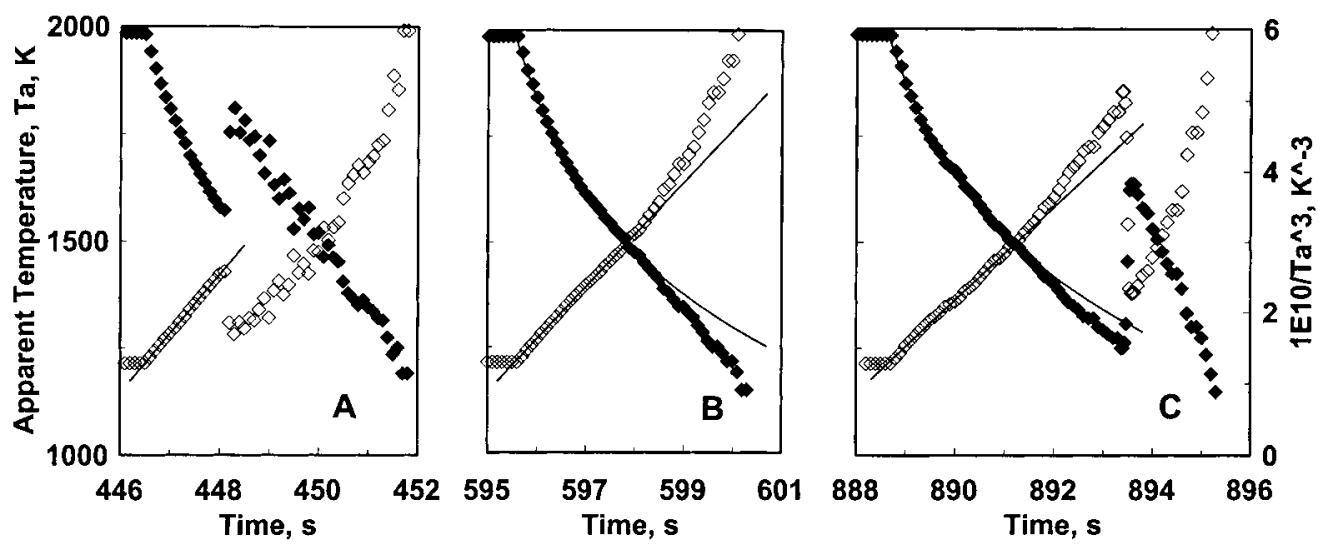

Fig. 3 Cooling curves for liquid YAG in the aero-acoustic levitator: (A) spontaneous crystallization to form $\mathrm{YAlO}_{3}$ and $\mathrm{Al}_{2} \mathrm{O}_{3}$; (B) glass formation; and (C) spontaneous crystallization to form $\mathrm{Y}_{3} \mathrm{Al}_{5} \mathrm{O}_{12}$.

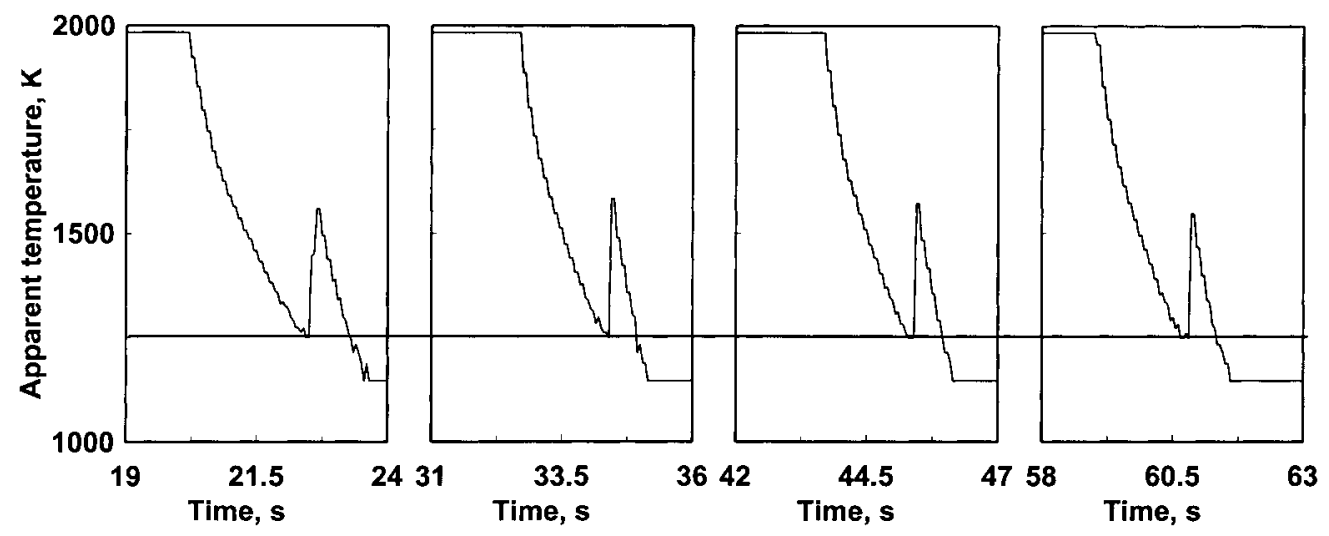

Fig. 4 Apparent temperature vs. time for molten $\mathrm{Y}_{3} \mathrm{Al}_{5} \mathrm{O}_{12}$ in the conical nozzle levitator. Reproducible nucleation of crystalline YAG is observed at $T_{a}=1250 \mathrm{~K}$. 
Figure 4 illustrates the cooling curves obtained when a YAG sample was processed in a conical nozzle levitator. Spontaneous crystallization to form pure YAG occurred at $T_{a}=1250 \pm 5 \mathrm{~K}$. If a slightly smaller sample is used in the aeroacoustic or conical nozzle levitators, the cooling rate increases, and glass is always formed upon cooling of the liquid.

The formation of YAP and $\alpha-\mathrm{Al}_{2} \mathrm{O}_{3}$ typically occurs upon first heating and melting of a fresh sample, and reproducible crystallization to YAG, nucleated at $T_{a}=1250 \mathrm{~K} \pm 5 \mathrm{~K}$, occurs after the sample has been heated and cooled a few times. It is possible that loss of oxygen or moisture from a fresh sample influences the phase selection. Sensitivity to the oxygen pressure is also found by using pure oxygen as the levitation gas flow, which allows glass formation at smaller cooling rates relative to processing in argon. Crystallization of an undercooled aluminum oxide melt leads to a dendritic and porous $\alpha-\mathrm{Al}_{2} \mathrm{O}_{3}$ in oxygen and dense prismatic crystals in argon [18]. Liquid aluminum oxide is also known to exhibit an optical absorption coefficient that varies with the ambient oxygen partial pressure [42].

\section{Nucleation temperature}

YAG nucleates from the undercooled melt at an apparent temperature, $T_{a, N}=1250 \pm 5 \mathrm{~K}$. Since the sample is not opaque, eq. 1 yields a lower limit, $T_{N}(\min )=1256 \pm 5 \mathrm{~K}$ on the true nucleation temperature when transparency is ignored in calculating the emissivity correction. The extrapolated fit of $1 / T_{a}{ }^{3} \mathrm{vs} . t$ data obtained at higher temperatures yields a larger value $T_{a, N}=1315 \pm 10 \mathrm{~K}$, averaged over several experiments. Application of the emissivity correction yields $T_{N}(\max )=1322 \pm 10 \mathrm{~K}$. This is an upper limit since, at lower temperatures, convective heat loss can cause a departure of the apparent temperature from the radiative cooling curve. Thus, $1256 \mathrm{~K}<T_{N}(\mathrm{YAG})<1322 \mathrm{~K}$.

\section{Polyamorphism in rare-earth aluminate glasses}

The glass product formed from the pure YAG composition contains spheroids of one glass in a matrix of a second glass. The two glass phases are of practically identical composition. This polyamorphism was first described by Aasland and McMillan [36], who employed rapid cooling of liquid samples supported on an iridium filament. With containerless methods, we obtained two-phase glass materials at 23-42 mol \% yttria [30]. At 28.7 mol \% yttria [36], the $\mathrm{Y}:(\mathrm{Y}+\mathrm{Al})$ composition ratios were $0.7128 \pm 0.0032$ (population standard deviation) for the spheroid phase and $0.7123 \pm 0.0012$ for the matrix phase. Our results for a pure YAG-composition glass were $\mathrm{Y}:(\mathrm{Y}+\mathrm{Al})=0.6243 \pm 0.0009$ for the spheroid phase and $0.6245 \pm 0.0010$ for the matrix phase [30]. Thus, the two glass phases have identical compositions, within approximately 0.001 in the component mol fractions.

Other rare-earth aluminate compositions form two-phase glasses under containerless cooling conditions, as shown in Table 1. Addition of lanthana to the melt resulted in single-phase glass [30].

Table 1 Single-phase and two-phase rare-earth aluminate glasses, balance $\mathrm{Al}_{2} \mathrm{O}_{3} \cdot R_{C}$ measured at 1300 $\mathrm{K}$ under containerless conditions.

\begin{tabular}{lllll}
\hline $\mathrm{Mol} \% \mathrm{Y}_{2} \mathrm{O}_{3}$ & $\mathrm{Mol} \% \mathrm{La}_{2} \mathrm{O}_{3}$ & $\mathrm{Mol} \% \mathrm{Re}_{2} \mathrm{O}_{3}$ & Phases & $R_{C}, \mathrm{~K} / \mathrm{s}$ \\
\hline $23-42$ & 0 & 0 & 2 & \\
37.5 & 0 & 0 & 2 & 70 \\
0 & 0 & $37.5 \mathrm{Lu}_{2} \mathrm{O}_{3}$ & 2 & $>110$ \\
0 & 0 & $37.5 \mathrm{Er}_{2} \mathrm{O}_{3}$ & 2 & 110 \\
12.5 & 12.5 & $12.5 \mathrm{Er}_{2} \mathrm{O}_{3}$ & 1 & 40 \\
0 & 37.5 & 0 & 1 & $<40$ \\
0 & 50.0 & 0 & 1 & $<40$ \\
$\leq 32.5$ & 25 & 0 & 1 & \\
0 & 5 & $32.5 \mathrm{Nd}_{2} \mathrm{O}_{3}$ & 1 & \\
0 & 7 & $30.5 \mathrm{Er}_{2} \mathrm{O}_{3}$ & 1 & \\
\hline
\end{tabular}




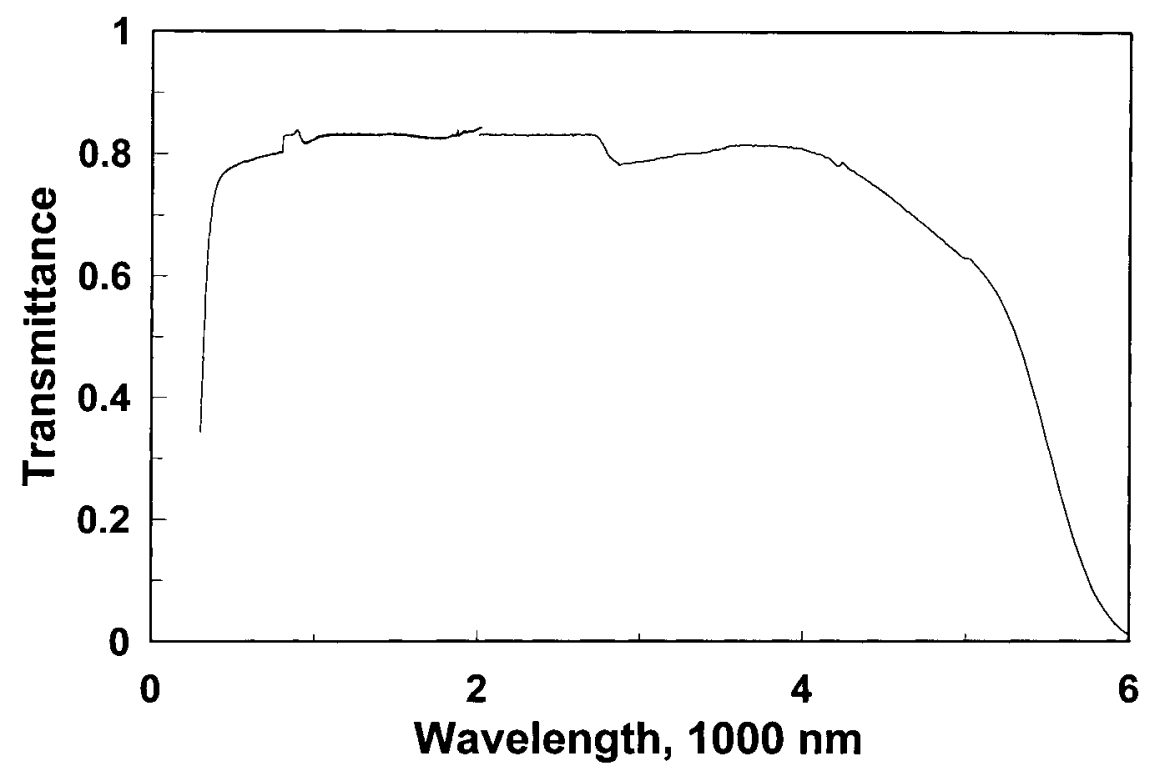

Fig. 5 Optical transmittance of $\mathrm{La}_{3} \mathrm{Al}_{5} \mathrm{O}_{12}$-composition glass, 2.1-mm thickness.

Table 1 includes critical cooling rates for glass formation, $R_{C}$, which decreases with lanthana additions, allowing larger specimens of glass to be obtained. The optical transmission of a single-phase lanthanum aluminate glass is shown in Fig. 5 [43].

A two-phase $\mathrm{Y}_{3} \mathrm{Al}_{5} \mathrm{O}_{12}$ composition glass gave Vickers hardness equal to 1000 and 900 on the spheroid and matrix glasses, respectively. The indenter caused cracks in the spheroid phase suggesting that the hardness value exceeds the derived result.

\section{Structure of aluminate liquids}

Coutures et al. [22] performed NMR measurements on aluminate liquids levitated in a CNL, to show that the concentration of 4-coordinated $\mathrm{Al}^{3+}$ ions is $60 \%, 80 \%$, and $95 \%$ in liquid $\mathrm{Al}_{2} \mathrm{O}_{3}, \mathrm{YAG}$, and $\mathrm{CaAl}_{2} \mathrm{O}_{4}$, respectively, the balance being 5- and 6-coordinated. This trend is consistent with increasing 4-coordination of $\mathrm{Al}^{3+}$ with the size of the added metal ion. Since $\mathrm{La}^{3+}$ is the largest rare-earth ion, it appears that the formation of single-phase glasses at a lower $R_{C}$ relative to lanthana-free melts arises from an increase in the concentration of 4-coordinated $\mathrm{Al}^{3+}$ ions.

Weber et al. [44] performed X-ray scattering on molten YAG levitated in a CNL. They obtained radial distribution functions and mean first-shell coordination of $\mathrm{Al}^{3+}$ and $\mathrm{Y}^{3+}$ ions at temperatures from $1768-2227 \mathrm{~K}$ (i.e., from 472 to $13 \mathrm{~K}$ below the $2240 \mathrm{~K}$ melting point of crystalline YAG). Radial distribution function peaks were at $r \approx 1.80 \AA$ for $\mathrm{Al}-\mathrm{O}$ and $r \approx 2.25 \AA$ for $\mathrm{Y}-\mathrm{O}$, consistent with 4 - and 6-coordination, respectively. In pure argon the Al-O distance and coordination number increased with undercooling. EXAFS measurements on molten YAG $[23,24]$ indicate a decrease in the mean $\mathrm{Y}-\mathrm{O}$ coordination number from 8 in YAG to 7.4 in the melt.

\section{SUMMARY}

Levitation techniques are a practical means for laboratory investigations of molten materials at very high temperatures, free from contamination by containers, in highly nonequilibrium conditions, under controlled temperature and ambient pressure, and with good optical access to specimens for noncontact 
property measurements. X-ray scattering, ellipsometry, drop oscillation, and shape relaxation studies have allowed structural, optical property, surface tension, and viscosity measurements on the liquid state. Deep undercooling under containerless conditions has allowed crystal nucleation, phase selection, liquid-liquid phase transitions, glass formation, and other phenomena to be investigated. The impact of levitation methods has been strong in the study of fragile liquids such as molten YAG, which displays a low viscosity at the melting point and highly non-Arhennian change of viscosity with temperature in the undercooled state. Remaining challenges for levitation hardware include the control of sample temperature gradients in laser beam heating techniques and control of fluid motion to allow high-precision transport property measurements. An apparatus for microgravity experimentation is under development that employs beam heating and electrostatic positioning with potential to meet these challenges.

\section{ACKNOWLEDGMENTS}

This research was partially supported by NASA Microgravity Research Division under Contract No. NAS8-40847 and NAS8-98092.

\section{REFERENCES}

1. N. Kitamura et al. Jpn. J. Appl. Phys. 39, L324-L326 (2000).

2. O. Muck. German patent no. 42204 (Oct. 30, 1923).

3. Team TEMPUS. In Materials and Fluids Under Low Gravity, Proc. IXth Symp. on GravityDependent Phen. in Physical Sciences, L. Ratke et al. (Eds.), Springer (1995).

4. W.-K. Rhim et al. Rev. Sci. Instrum. 54, 307-317 (1985).

5. A. J. Rulison, J. L. Watkins, B. Zambrano. Rev. Sci. Instrum. 68, 2856-63 (1997).

6. Jan Rogers. NASA Marshall Space Flight Center, private communication, March 2000.

7. W-K. Rhim, K. Ohsaka, P-F. Paradis. Rev. Sci. Instrum. 70, 2796-2801 (1999).

8. J. Granier and C. Potard. In Proc. 6th Eur. Symp. Micrograv. Bordeaux, France, ESA SP-256 (1987), pp. 421-25.

9. J.-Ch. Barbe et al. Int. J. Thermophys. 20, 1071-83 (1999).

10. P. C. Nordine and R. M. Atkins. Rev. Sci. Instrum. 53, 1456 (1982).

11. S. Krishnan et al. High Temp. Science 31, 45 (1991).

12. J. K. R. Weber et al. Rev. Sci. Instrum. 65, 456-465 (1994).

13. J. K. R. Weber et al. J. Jpn. Soc. Microgravity Appl. 13, 27-35 (1996).

14. R. F. Cooper. et al. Science 274, 1173-76 (1996).

15. J. K. R. Weber et al. J. Am. Ceram. Soc. 76 9., 2139-41 (1993).

16. J. R. Olive et al. J. Mater. Res. 9, 1-3 (1994).

17. J. K. R. Weber et al. J. Mater. Res. 9, 1657-1660 (1994).

18. J. K. R. Weber et al. J. Am. Ceram. Soc. 78, 577-582 (1995).

19. A. B. Biswas, J. K. R. Weber P. C. Nordine. J. Mat. Res. 10, 1823-27 (1995).

20. D. A. Winborne et al. Metall. Trans. 7B, 711 (1976).

21. J. P. Coutures et al. In Proc. $6^{\text {th }}$ European Symposium on Materials Sciences Under Microgravity Conditions, Bordeaux, France, 2-5 December, 1986, pp. 427-30.

22. J.-P. Coutures et al. C. R. Acad. Sci. Paris 310, Série II. 1041-45 (1990).

23. X. Launay et al. C. R. Acad. Sci. Paris, 324, Série II, 527-35 (1997).

24. C. Landron et al. Europhys. Lett. 44, 429-435 (1998).

25. S. Krishnan et al. Rev. Sci. Instrum. 68, 3512-3518 (1997).

26. S. Krishnan and D. L. Price. J. Phys.: Condens. Matter 12, R145-R176 (2000).

27. J. E. Enderby et al. Appl. Phys. Lett. 71, 116-118 (1997).

28. J. K. R. Weber, J. J. Felten, B. Cho, P. C. Nordine. Nature 393, 769-771 (1998).

29. B. Glorieux et al. Int. J. Thermophys. 20, 1085-94 (1999).

(C) 2000 IUPAC, Pure and Applied Chemistry 72, 2127-2136 
30. J. K. R. Weber et al. J. Am. Ceram. Soc. 83, 1868-72 (2000).

31. S. Krishnan. Thermophysical and Optical Property Measurements of Electromagnetically Levitated Liquid Metals, Ph.D Thesis, Rice University, 1989.

32. S. Krishnan et al. High Temp. Sci. 29, 17 (1990).

33. J. L. Caslavsky and D. J. Viechnicki. J. Mat. Sci. 15, 1709-18 (1980).

34. C. A. Angell. Science 267 1624-35 (1995).

35. V. J. Fratello and C. D. Brandle. J. Cryst. Growth 128, 1006-1010 (1993).

36. S. Aasland and P. F. McMillan. Nature 369, 633-639 (1994).

37. W. Kauzmann. Chem Rev. 43, 219-56 (1948).

38. M. W. Chase, Jr., et al. JANAF Thermochemical Tables Third Edition, J. Phys. Chem Ref. Data 14 (1985).

39. M. Gervais et al. J. Am. Ceram. Soc. 75, 3166-68 (1992).

40. I-Ching Lin et al. J. Non-Cryst. Solids 243, 273-276 (1999).

41. K. Nagashio and K. Kuribayashi. J. Mat. Res. In press.

42. J. K. R. Weber et al. J. Am. Ceram. Soc. 78, 583-587 (1995).

43. J. K. R. Weber, et al. J. Appl. Phys. Submitted for publication, Jan. 2001.

44. J. K. R. Weber et al. Phys. Rev. Lett. 84, 3622-25 (2000). 